Original Article

\title{
Effects of Phytolacca decandra on the viability of murine breast adenocarcinoma (4T1 cells) in vitro
}

\author{
William A. Santos, Thaís C. Silva, Sandra A. G. Pinto, Vanessa Xavier, Elizabeth C. Perez, Leoni \\ V. Bonamin*
}

Universidade Paulista, São Paulo, Brazil. E-mail: *leonibonamin@gmail.com

\begin{abstract}
Background: Comparative studies in cancer patients using conventional and alternative therapy have demonstrated that Phytolacca decandra in homeopathic potencies increases survival and improves quality of life of patients bearing breast cancer. In vitro studies show the induction of apoptosis pathways in MCF-7, a human breast cancer cells lineage, after treatment with Phytolacca decandra in different homeopathic dilutions (from 30C to 10M). Recently, we observed significant growth reduction of Ehrlich carcinoma in mice treated with Phytolacca decandra $30 \mathrm{cH}$.

Aims: To evaluate Phytolacca decandra effect in different homeopathic dilutions on the phenotypic features, apoptosis index, and cell morphology of 4T1 cells (murine carcinoma cell lineage) in vitro.

Method: The potencies 6, 12, 30 and 200- $\mathrm{CH}$ preparer sterile pure water were studied. Dynamized sterile pure water was used as control. The cytotoxicity was evaluated after different cell treatments in culture bottles $(25 \mathrm{ml})$ with the homeopathic medicines (equal to $10 \%$ of total medium volume). Cells were cultured in a cell density of $5 \times 10^{5}$ cells / ml, treated with the respective potency and, after 24 houns, analyzed for the apoptosis index using Annexin V kit and measured using the Countess ${ }^{\circledR}$ System. The-morphology of the 4T1 cells was monitored by staining fixed cell smears with hematoxylin-eosin method. Cells were previously adhered to a glass cover slip and fixed with absolute methanol. The samples werevaluated in quadruplicate and the data were analyzed by one-way ANOVA.
\end{abstract}

Results and discussion: The results obtained up to now show that the treatment with Phytolacca decandra $200 \mathrm{cH}$ induced increase of apoptosis index in relation to the control. Moreover, morphological changes were observed in the respective cell smears: the presence of multinucleated cells, some of them presenting up to 8 nuclei and the increase of eosinophilic staining pattern of cytoplasm, even in mononucleated cells.

Conclusion: The increase in apoptosis index reproduced the results described in the literature with other cell lineages, but the changes in morphology still deserve further evaluation.

Keywords: breast adenocarcinoma, 4T1 cells, in vitro models, homeopathy, Phytolacca decandra.

Received: March 1, 2018. Accepted: April 26, 2018.

(C) International Journal of High Dilution Research.

Not for commercial purposes. 